\title{
Vasoactive intestinal peptide as a new drug for treatment of primary pulmonary hypertension
}

\author{
Ventzislav Petkov, ${ }^{1}$ Wilhelm Mosgoeller, ${ }^{2}$ Rolf Ziesche, ${ }^{1}$ Markus Raderer, ${ }^{3}$ \\ Leopold Stiebellehner, ${ }^{1}$ Karin Vonbank, ${ }^{1}$ Georg-Christian Funk, ${ }^{1}$ Gerhard Hamilton, ${ }^{4}$ \\ Clemens Novotny, ${ }^{5}$ Bernhard Burian, ${ }^{1}$ and Lutz-Henning Block ${ }^{1}$ \\ ${ }^{1}$ Department of Internal Medicine, Division of Pulmonary Medicine, University of Vienna, Medical School, Vienna, Austria
${ }^{2}$ Institute of Cancer Research, University of Vienna, Vienna, Austria
${ }^{3}$ Department of Internal Medicine, Division of Oncology, University of Vienna, Medical School, Vienna, Austria
${ }^{4}$ Ludwig Boltzmann Institute of Clinical Oncology, KH Lainz, Vienna, Austria
${ }^{5}$ Department of Nuclear Medicine, University of Vienna, Medical School, Vienna, Austria
}

Primary pulmonary hypertension is a fatal disease causing progressive right heart failure within 3 years after diagnosis. We describe a new concept for treatment of the disease using vasoactive intestinal peptide, a neuropeptide primarily functioning as a neurotransmitter that acts as a potent systemic and pulmonary vasodilator. Our rationale is based on the finding of a deficiency of the peptide in serum and lung tissue of patients with primary pulmonary hypertension, as evidenced by radioimmunoassay and immunohistochemistry. The relevance of this finding is underlined by an upregulation of corresponding receptor sites as shown by Northern blot analysis, Western blot analysis, and immunological techniques. Consequently, the substitution with the hormone results in substantial improvement of hemodynamic and prognostic parameters of the disease without side effects. It decreased the mean pulmonary artery pressure in our eight study patients, increased cardiac output, and mixed venous oxygen saturation. Our data provide enough proof for further investigation of vasoactive intestinal peptide and its role in primary pulmonary hypertension.

J. Clin. Invest. 111:1339-1346 (2003). doi:10.1172/JCI200317500.

\begin{abstract}
Introduction
The typical pathological findings in patients with primary pulmonary hypertension $(\mathrm{PPH})$ are confined to the right heart and lung. The disease is uncommon; its prognosis is usually fatal. Pathological examination of the pulmonary arteries of PPH patients reveal impairment of vascular and endothelial homeostasis that is evidenced from a reduced synthesis of prostacyclin and NO $(1,2)$ and an increased production of thromboxane and endothelin-1 $(1,3)$. Prostacyclin and its analogues are potent vasodilators and inhibitors of both platelet aggregation and smooth muscle cell proliferation $(4,5)$ and are presently being applied for the treatment of $\mathrm{PPH}(6,7)$. Pharmacologically, however, most prostanoids are unstable, an aspect that limits their efficacy, especially when given continuously. Thus, an alternative approach to the management of PPH might be the application of
\end{abstract}

Received for publication December 1, 2002, and accepted in revised form February 25, 2003.

Address correspondence to: L.-H. Block, University of Vienna, Department of Internal Medicine, Waehringer Guertel 18-20, A-1090 Vienna, Austria. Phone: 431-40400-4774;

Fax: 431-40400-4784; E-mail: lutz-henning.block@akh-wien.ac.at. Conflict of interest: The authors have declared that no conflict of interest exists.

Nonstandard abbreviations used: primary pulmonary hypertension (PPH); vasoactive intestinal peptide (VIP); pulmonary artery smooth muscle cells (PASMCs); mean pulmonary arterial pressure (MPAP). another potent vasodilator with more favorable pharmacokinetic and pharmacodynamic features.

Among the various hormones of the human body, the vasoactive intestinal peptide (VIP) shows striking pharmacological characteristics that might be worthy of testing for its ability in combating PPH. Hence, we hypothesized that VIP may play a role in the pathogenesis of PPH and could be used as a treatment for the disease. VIP belongs to the glucagon-growth hormone-releasing factor secretion superfamily. The sequence has been remarkably well conserved during the evolution from protochordates to mammals, suggesting an important biological function. VIP consists of 28 amino acids with a molecular weight of 3,326 Da; it has been described as a neuroendocrine mediator with an important role in the water and electrolyte secretion in the gut $(8,9)$. In addition, VIP acts as a potent systemic vasodilator and decreases pulmonary artery pressure and pulmonary vascular resistance in monocrotaline-induced pulmonary hypertensive rabbits (10) and in healthy individuals (11-13); it inhibits platelet activation (14) and vascular smooth muscle cell proliferation (15). Recently, VIP has been shown to prevent experimentally induced arthritis in mice (16). These biological effects are mediated by specific VIP receptors (VPAC-1 and VPAC-2) expressed on the cell surface membrane of normal and various neoplastic tissues $(17,18)$. The presence of VPAC receptors has been shown on airway epithelia, on macrophages surrounding capillaries, and in the subintima of 
Table 1

Baseline characteristics of the patients

$\begin{array}{cccccccc}\text { No. } & \text { Age }(\mathrm{yr}) & \text { Sex } & \text { NYHA class } & \text { Weight }(\mathrm{kg}) & \text { Diagnosis } & \text { Previous or concomitant treatment } & \text { Time since diagnosis (mo) } \\ 1 & 47 & \text { F } & \text { IV } & 61 & \mathrm{PPH} & \text { Diuretics, antithrombotic agents } & 18 \\ 2 & 33 & \text { F } & \text { III } & 58 & \mathrm{PPH} & \text { Antithrombotic agents } & 6 \\ 3 & 60 & \text { F } & \text { IV } & 70 & \mathrm{PPH} & \text { Diuretics, antithrombotic agents, Ca-channel blockers } & 24 \\ 4 & 52 & \text { M } & \text { III } & 78 & \mathrm{PPH} & \text { Antithrombotic agents } & 14 \\ 5 & 26 & \text { F } & \text { III } & 52 & \mathrm{PPH} & \text { Antithrombotic agents } & 8 \\ 6 & 33 & \text { F } & \text { IV } & 62 & \mathrm{PPH} & \text { Diuretics, antithrombotic agents } & 30 \\ 7 & 51 & \text { F } & \text { IV } & 82 & \mathrm{PPH} & \text { Diuretics, antithrombotic agents } & 26 \\ 8 & 54 & \text { M } & \text { III } & 83 & \mathrm{PPH} & \text { Diuretics, antithrombotic agents, supplemental oxygen } & 24\end{array}$

pulmonary arteries and veins $(19,20)$. Stimulation of VPAC receptors leads to the activation of the cAMP and cGMP system. Analogously, cAMP- and cGMP-dependent pathways have been shown to mediate the action of prostacyclins, $\mathrm{NO}$, and phosphodiesterase inhibitors in the treatment of pulmonary hypertension $(5,21)$.

Here were present preclinical and preliminary clinical data suggesting that PPH may be associated with a VIP deficiency in serum and lung tissue.

\section{Methods}

Scintigraphic imaging and analysis. The ${ }^{123}$ I-VIP distribution was recorded following intravenous injection in four healthy individuals according to a standard protocol (18).

Serum VIP, tissue sampling, and cell culture. VIP serum concentration was determined by radioimmunoassay (123I-VIP RIA; Immuno-Biological Laboratories, Hamburg, Germany), with a detection threshold at $10 \mathrm{pg} / \mathrm{ml}$. We determined the VIP serum concentration in 45 healthy controls, in eight PPH clinical study patients, and in an additional four patients with PPH who did not meet the inclusion criteria for the clinical study. The latter four patients were on prostacyclin therapy and were, therefore, excluded from the VIP trial. Additionally, 45 patients suffering from pancreatic cancer served as positive controls. A previous investigation had reported a relative instability of VIP following drawing of blood (22); we therefore treated the patients' sera with trasylol to prevent degradation of the peptide.

For immunostaining, tissue was obtained from 12 patients subjected to lobectomy, without PPH and asthma, and $12 \mathrm{PPH}$ patients from the archive. Tissue donation was regulated by the national ethical committee and national law.

For Western and Northern blot receptor analysis we used cultured pulmonary artery smooth muscle cells (PASMCs) obtained from five PPH patients undergoing lung transplantation and five lung tumor control patients. Lung lobes were dissected and peripheral arteries (diameter $1 \mathrm{~mm}$ ) digested in HBSS containing $2.0 \mathrm{mg} / \mathrm{ml}$ collagenase in RPMI culture medium for 10 min (Sigma-Aldrich Handels GmbH, Vienna, Austria). The adventitia and endothelium were removed, the remaining media containing $2.0 \mathrm{mg} / \mathrm{ml}$ collagenase, $1.0 \mathrm{mg} / \mathrm{ml}$ elastase, and $1.0 \mathrm{mg} / \mathrm{ml} \mathrm{BSA} \mathrm{(Sigma-}$ Aldrich, St Louis, Missouri, USA) was digested at $37^{\circ} \mathrm{C}$.
The cells were then resuspended in Sm-BM medium (Clonetics, Rockland, California, USA) with $10 \%$ FCS (PAA, Linz, Austria), $100 \mathrm{U} / \mathrm{ml}$ penicillin (PAA), and $100 \mu \mathrm{g} / \mathrm{ml}$ streptomycin (PAA), and seeded into culture flasks. Following fixation in ice-cold methanol, identification of the cells was done by immunostaining for vascular smooth muscle $\alpha$-actin (Sigma A2547; SigmaAldrich Handels $\mathrm{GmbH}$ ). Preparations with more than $90 \%$ PASMCs were used for experiments.

Immunohistochemistry for VIP protein and VIP receptors. Rehydrated paraffin sections were stained for VIP and VIP receptors. Following antigen retrieval in $5 \mathrm{mM}$ EDTA/PBS ( $\mathrm{pH} 8$ ) for $60 \mathrm{~min}$ at $95^{\circ} \mathrm{C}$ and unspecific protein blocking in 5\% BSA, 0.3\% Tween-20 (Merck, Darmstadt, Germany), and 0.3\% Triton-X 100, the sections were either incubated with rabbit anti-VIP Ab's (INCSTAR Corp., Stillwater, Minnesota, USA) diluted 1:750 in commercially available Ab diluent (DAKO A/S, Glostrup, Denmark) for $17 \mathrm{~h}$, or with mouse anti-VPAC1 immunoglobulins (Exalpha Biologicals, Boston, Massachusetts, USA) diluted 1:200 in Ab diluent, or with mouse anti-VPAC-2 immunoglobulins (Exalpha Biologicals) diluted $1: 100$ for $16 \mathrm{~h}$ at $4^{\circ} \mathrm{C}$. Binding sites were visualized with biotinylated secondary Ab's (DAKO

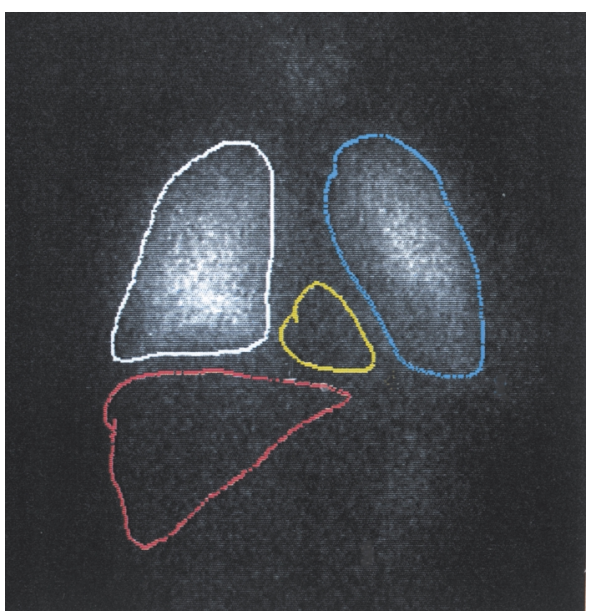

\section{Figure 1}

VIP scintigraphy. Intravenous injection of 123 I-VIP and scintigraphy in a healthy individual showing high intensities over the lung (outlined in white and blue) as compared with the region over the heart (yellow line) and liver (red line). 


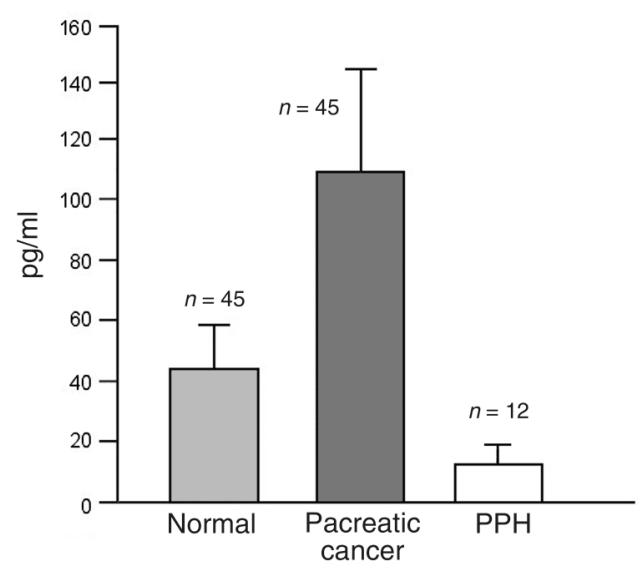

Figure 2

VIP serum concentration. VIP serum concentration as determined by RIA of control individuals, pancreatic cancer patients, and $\mathrm{PPH}$ patients.

A/B), streptavidin-HRP, and diaminobenzidine and counterstained with hematoxylin (Sigma-Aldrich). Omission of the primary $\mathrm{Ab}$ or preabsorption with the corresponding antigen served as control.

Immunocytochemistry. PASMCs were fixed, rinsed, and incubated for unspecific protein blocking. Primary Ab's were mouse anti-VPAC-1 immunoglobulins (Exalpha Biologicals) or mouse anti-VPAC-2 (Exalpha Biologicals), both diluted 1:100 in $\mathrm{Ab}$ diluents (DAKO A/B) in a moist chamber for $50 \mathrm{~min}$ at $37^{\circ} \mathrm{C}$. Secondary Ab's were FITC-labeled goat anti-mouse immunoglobulins (Sigma-Aldrich Handels $\mathrm{GmbH}$ ). Slides were rinsed in PBS and mounted in antifade medium (Citifluor; Groepl, Tulln, Austria) containing DAPI $(0.1 \mu \mathrm{g} / \mathrm{ml})$.

Western blot analysis of VPAC receptors. Cells were harvested, resuspended in $1 \mathrm{mM} \mathrm{Na}_{3} \mathrm{VO}_{4}$, washed twice in ice-cold PBS/ $1 \mathrm{mM} \mathrm{Na}_{3} \mathrm{VO}_{4}$, and then lysed in RIPA-II buffer $(500 \mathrm{mM} \mathrm{NaCl}, 50 \mathrm{mM}$ Tris/HCl, pH 7.4, 0.1\% SDS, $1 \% \mathrm{NP}-40,0.5 \% \mathrm{Na}-\mathrm{DOC}, 0.05 \% \mathrm{NaN}_{3}, 1 \mathrm{mM}$ $\mathrm{Na}_{3} \mathrm{VO}_{4}$, plus Complete Protease Inhibitor cocktail) for $30 \mathrm{~min}$ on ice. Sonicated cells were centrifuged to obtain the membrane fraction. Protein concentration was estimated by the Bradford technique (23). Twenty micrograms of membrane protein were separated by gel electrophoreses in 12\% SDS-polyacrylamide gels (Bio Rad Laboratories GmbH, Munich, Germany). Blotting on PVDF-membrane (Pall Corp., Ann Arbor, Michigan, USA) was performed overnight. Membranes stained with Ponceau red were then blocked with 5\% (wt/vol) milk powder/PBS/0.5\% Tween. For detection of VIP receptors, monoclonal anti-VPAC-1 or monoclonal anti-VPAC-2 Ab's (1:100; Exalpha Biologicals Inc., Watertown, Massachusetts, USA) were added overnight and visualized with a peroxidase-conjugated secondary $\mathrm{Ab}$ (rabbit anti-mouse diluted 1:100; DAKO $\mathrm{A} / \mathrm{B})$, using the West Pico Chemiluminescence Kit (Pierce Chemical Co., Rockford, Illinois, USA).

Total RNA extraction and Northern blot analysis. PASMCs were homogenized in Trizol reagent. Total RNA was extracted according to the manufacturer's instructions (Invitrogen, Lofer, Austria). Transfer of $20 \mu \mathrm{g}$ of total RNA onto a S \& S Nytran membrane (Schleicher \& Schuell GmbH, Vienna, Austria) was done by capillary blotting overnight followed by UV cross-linking. Specific probes for hybridization were generated from plasmids by restriction. Following agarose gel separation, the probes were purified with the Qiaex gel purification kit (Amersham International, Amersham, United Kingdom) and $\left.{ }^{32} \mathrm{P}\right] \mathrm{dCTP}$ (Amersham International). Hybridization was on membranes prehybridized at $42^{\circ} \mathrm{C}$ in a hybridization solution containing $50 \%$ formamide, $5 \times$ Denhardt's solution, $5 \times$ SSC, and $0.1 \%$ SDS. Exposure was on an $x$-ray film (Hyperfilm; Amersham International).

Radioligand-binding studies. One million PASMCs from PPH patients and controls were washed in HEPES buffer $(120 \mathrm{mM} \mathrm{NaCl}, 4 \mathrm{mM} \mathrm{KCl}, 2.6 \mathrm{mM}$ $\mathrm{KH}_{2} \mathrm{PO}_{4}, 2 \mathrm{mM} \mathrm{CaCl}_{2}, 0.6 \mathrm{mM} \mathrm{MgCl}_{2}, 14 \mathrm{mM}$ D-glucose, and $25 \mathrm{mM}$ HEPES) with $0.1 \% \mathrm{BSA}$. Incubation with increasing concentrations $(0.01-20 \mathrm{nM})$ of ${ }^{125}$ I-labeled VIP (New England Nuclear Corp., Boston, Massachusetts, USA) in the absence (total binding) and the presence of the same unlabeled ligand (100 $\mathrm{nM}$, nonspecific binding) was performed at $4^{\circ} \mathrm{C}$. Each assay was made in triplicate. After 60 minutes of incubation, the reaction mixture was diluted 1:10 with assay buffer $\left(4^{\circ} \mathrm{C}\right)$ and centrifuged $(5,000 \mathrm{~g}, 10$ $\min , 4^{\circ} \mathrm{C}$ ) to separate membrane-bound from free ligand. The resulting pellet was counted in a $\gamma$ counter (Cobra-II; GMI Inc., Albertville, Minnesota, USA) for $1 \mathrm{~min}$. Specific binding was calculated as the difference between total and nonspecific binding according to Scatchard (24) by using the program Origin (1994 version; Microcal Software, Northampton, Massachusetts, USA) (25).

\begin{abstract}
Figure 3
VIP expression in lung tissue. (a) The immunohistochemical staining of VIP in nerve fibers that were found within media and media-adventitia junctions in pulmonary resistance vessels of healthy (normal) controls. (b) In contrast, PPH patients show a thickened vessel wall and plexiform lesions without any specific VIP staining (scale bar $=20 \mu \mathrm{m}$ ). Arrows indicate VIP immunoreactive fibers.
\end{abstract}
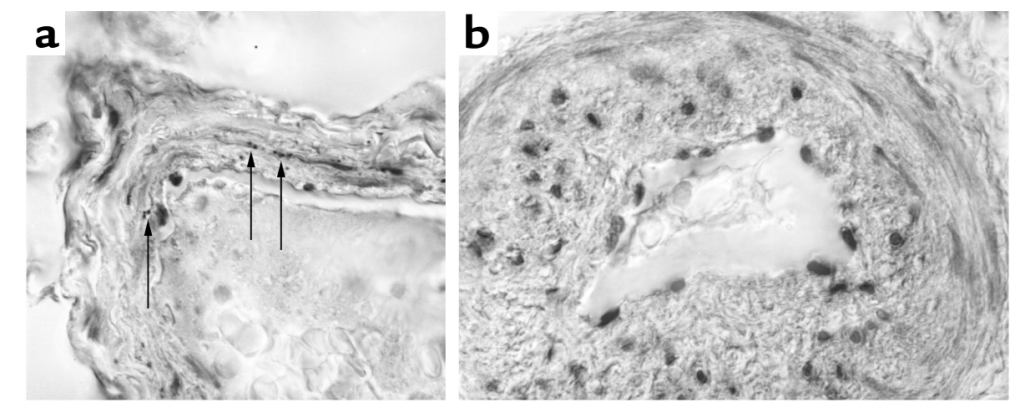

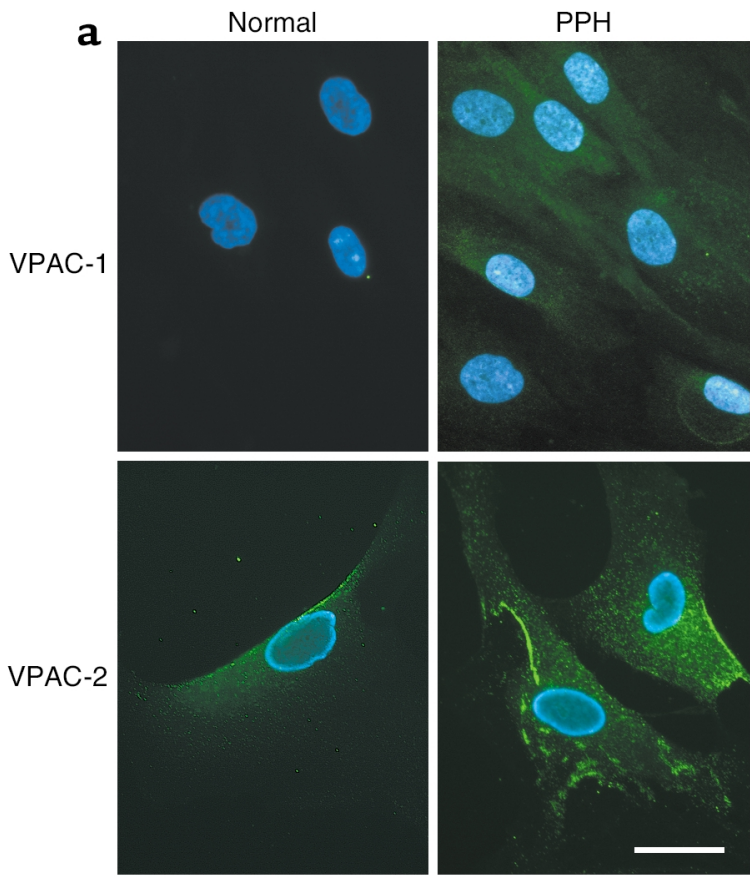

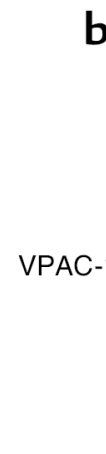

b

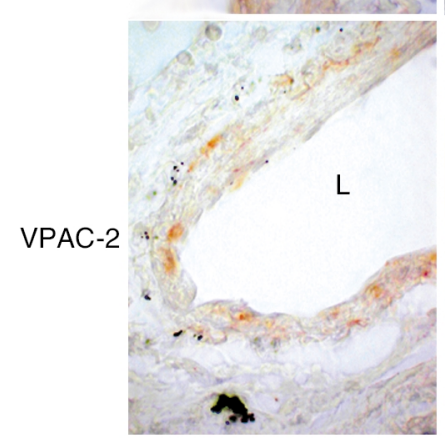

Normal

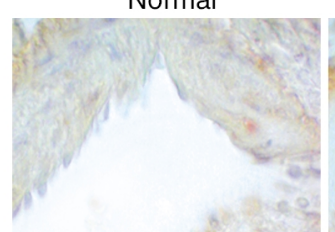

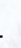
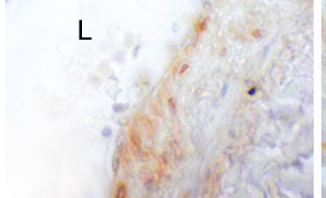

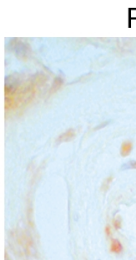

$\mathrm{PPH}$

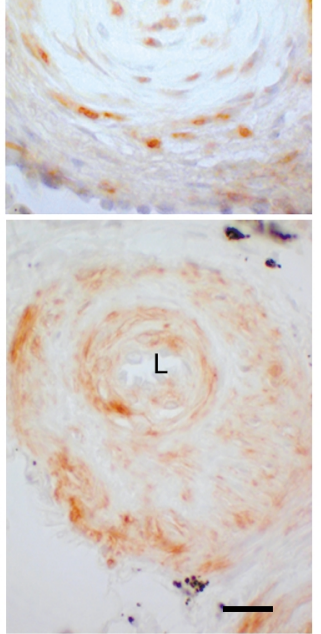

\section{Figure 4}

VIP-receptor immunostaining. (a) Immunocytochemical staining of cultured PASMCs. VPAC-1 shows weak and VPAC-2 strong expression in normal controls. Both are enhanced in PPH patients (scale bar $=10 \mu \mathrm{m})$. (b) Immunohistochemical staining of pulmonary blood vessels in paraffin-embedded lung tissue. Normal controls show a regular vessel wall and a wide lumen ( $L$ ). VPAC- 1 staining shows a tendency toward a zonal distribution of the receptors in the media, while the signal for VPAC-2 is distributed more evenly throughout the whole media. In PPH the vessels show a narrowing of the lumen. Both receptors, particularly VPAC-2, are upregulated in PPH (scale bar $=20 \mu \mathrm{m})$.

Cell proliferation. PASMCs were counted (Sysmex cellcounter; Tao Medical Co., Tokyo, Japan) and transferred to microtiter plates (96 wells, $10^{4}$ cells/well in $100 \mu \mathrm{l}$ medium; Greiner Labortechnik , Kremsmuenster, Austria). Appropriate dilutions of test compounds were added to a total volume of $200 \mu \mathrm{l} /$ well and the plates incubated for 4 days under tissue-culture conditions. Solvent controls were included in all tests. Doseresponse curves were obtained by assessing twofold dilutions of the drugs in triplicate and used to calculate $\mathrm{IC}_{50}$ concentrations. Cell proliferation was quantified using a modified tetrazolium dye assay (EZ4U; Biomedica GmbH, Vienna, Austria) and measurement of the reduced formazan at $450 \mathrm{~nm}$ (ELISA reader; Eurogenetics, Tessenderlo, Belgium).

Clinical study. Between July 2000 and November 2001 we enrolled eight patients with severe PPH (New York Heart Association functional class III or IV) (Table 1), according to the diagnostic criteria of the National Institutes of Health Registry on PPH (26). The diagnosis of PPH was based on clinical assessment, right heart catheterization, echocardiography, spiral-computed tomography of the pulmonary arteries, pulmonary angiography, ventilation/perfusion lung scan, and complete lung function testing. Pulmonary hypertension as a result of heart disease, pulmonary disease, sleep-associated disorders, chronic thromboembolic disease, autoimmune or collagen vascular diseases, HIV infection, and liver disease was excluded. Patients treat- ed with anticoagulant drugs, diuretics, calcium-channel blockers, or supplemental oxygen were included. Patients with previous treatment of epoprostenol or prostacyclin analogues were excluded. Each patient gave informed consent to participate in the trial, and investigations were according to institutional guidelines and to the Declaration of Helsinki principles.

The clinical study was designed as a prospective, controlled intraindividual trial. To be eligible for the treatment with aerosolized VIP, patients had to have PPH

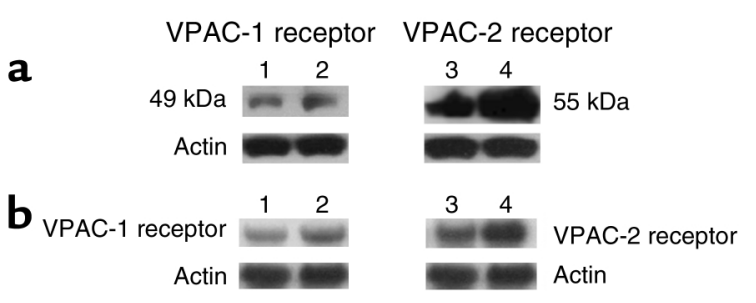

\section{Figure 5}

Receptor expression in cultured PASMCs. (a) Western blot analysis of VPAC- 1 and VPAC-2 (and actin as loading control) in PASMCs from controls and $\mathrm{PPH}$ patients, showing receptor upregulation, particularly of VPAC-2: lane 1, VPAC-1, control; lane 2, VPAC-1, PPH; lane 3, VPAC-2, control; lane 4, VPAC-2, PPH. (b) Northern blot analysis of VIP receptor expression showing upregulation of both receptor types, which is more marked for VPAC-2: lane 1, VPAC-1, control; lane 2, VPAC-1, PPH; lane 3, VPAC-2, control; lane 4, VPAC-2, $\mathrm{PPH}$. $\beta$-actin, control for equal loading of RNA. 
a

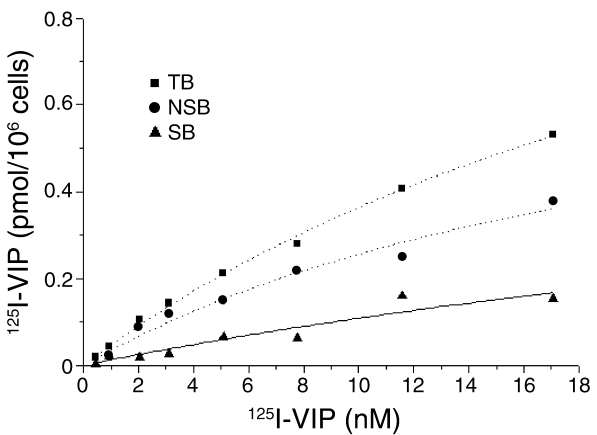

b

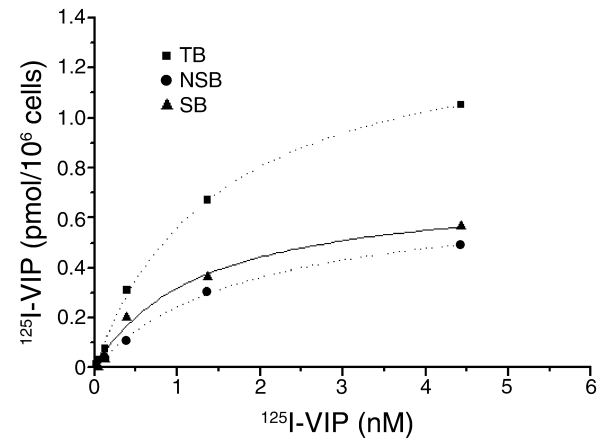

with severe limitation of exercise capacity refractory to conventional treatment, including calcium-channel blockers. The patients were evaluated on an inpatient basis at baseline and outpatient basis after 4, 8, 12, 16, and 24 weeks of therapy. The primary end point was the change from baseline to week-12 and -24 exercise capacity. Exercise capacity was determined by the 6-minute walk test (27). All tests were performed over the same route. The secondary measures of efficacy were the change from baseline to week 12 in the pulmonary hemodynamic and the change from base line to week 12 and 24 in the Borg dyspnea index (28) and the time of clinical worsening.

Statistical analysis. Baseline demographic, hemodynamic variables, and exercise capacity are presented as means plus or minus SD. Variables measured at baseline and during VIP inhalation in the same patients were compared by Wilcoxon signed rank test (twosided) for paired data. $P$ values less than 0.05 were considered statistically significant.

VIP serum levels were compared between the groups by means of the Student $t$ test, and by the Wilcoxon signed rank test when the data did not allow for computing the mean and standard deviations.

\section{Results}

VIP deficiency in PPH. To examine the distribution of VIP receptors in various organs of humans, scintigraphic analysis was applied using ${ }^{123} \mathrm{I}$-VIP as tracer. We revealed distinct expression of the VIP receptors with relatively higher density in lung tissue when compared with the regions over heart and liver (Figure 1).

Next, we determined the concentration of VIP in circulating blood of humans (Figure 2 ) by radioimmunoassay. VIP level in normal subjects $(n=45)$ was

\section{Figure 6}

Ligand-binding capacity in cultured PASMCs. Ligand binding of 125 I-VIP as a function of concentration to membranes of PASMCs cultured from healthy controls $(n=3)(\mathbf{a})$ and $\mathrm{PPH}$ patients $(n=3)$ (b). Cells $\left(10^{6}\right)$ were incubated for $60 \mathrm{~min}$ at $4{ }^{\circ} \mathrm{C}$ in the presence or absence of unlabeled VIP $(100 \mathrm{nM})$ with the various radioligand concentrations (0.01-20 nM). TB, total binding; NSB, nonspecific binding; SB, specific binding. (a) The data of controls, where the specific binding is below $0.3 \mathrm{pmol} / 6 \times 10^{6}$ cells; (b) $\mathrm{PPH}$ cells with an average specific binding well above $0.6 \mathrm{pmol} / 6 \times 10^{6} \mathrm{cells}$.

$42.4 \pm 17.1 \mathrm{pg} / \mathrm{ml}$. Increased VIP serum concentrations have been reported for neurogenic tumors, congenital sensory neuropathy, Crohn disease, ulcerative colitis, and pancreatic islet cell carcinoma (22). Similarly, we found elevated VIP serum concentration in pancreatic cancer patients $(n=45)$ of $111.7 \pm 46.2 \mathrm{pg} / \mathrm{ml}$. In contrast, VIP levels in the group of PPH patients $(n=12)$ were at the detection threshold of the assay (i.e., 10 $\mathrm{pg} / \mathrm{ml})$. This result was confirmed in eight patients when tested 8 weeks later.

VIP immunoreactive nerve fibers have been found previously in the median layer of pulmonary arteries of normal individuals (19, 20, 29). Analogously, immunochemical staining for the peptide in pulmonary arteries prepared from resected lungs of control patients revealed moderate expression of VIP (Figure 3a). The number of VIP immunoreactive nerve fibers in the control patients was $1.8 \pm 2.93$ per blood vessel $(n=40)$. In the explanted lung tissue of PPH patients the small blood vessels (diameter less than 0.3 $\mathrm{mm}$, with or without plexiform lesions) revealed a number similar to background levels as determined in a blinded analysis $(0.2 \pm 0,48, n=43)$ and was significantly lower (Student $t$ test, $P<0.01$; see also Figure $3 b)$ as compared with healthy subjects.

The visualization of VIP receptors in cultured cells by immunocytochemistry demonstrated that PASMCs express both receptor subtypes. In three experiments a minimum of 100 cells were evaluated per

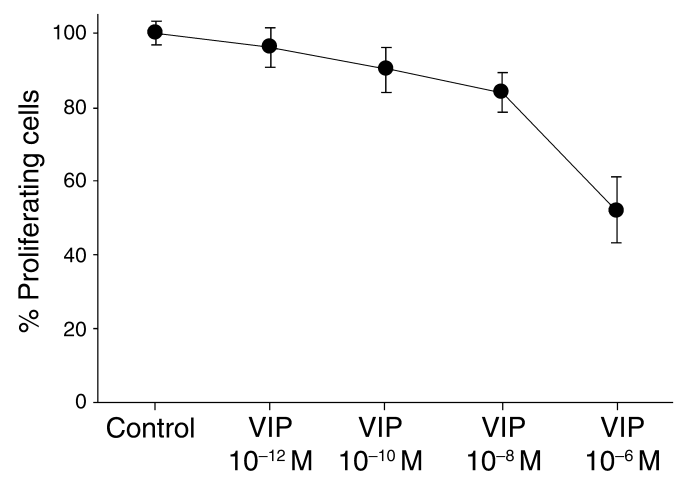

Figure 7

Basal proliferation of PASMCs by VIP. VIP inhibited basal proliferation of PASMCs from PPH patients. This inhibitory effect was dose dependent. 


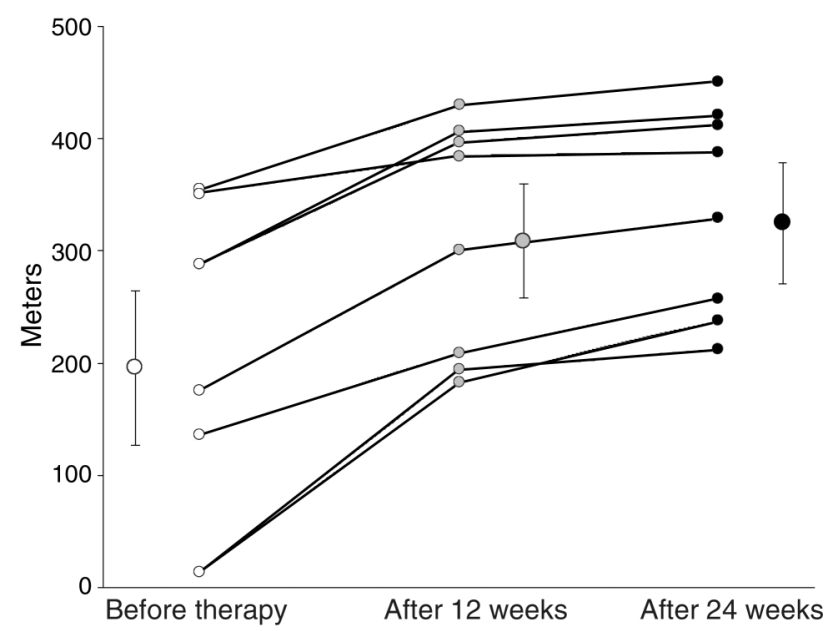

Figure 8

Six-minute walk test. Physical exercise improvement as determined by the achieved walk distance in meters during the 6 -minute walk test. Individual data for all eight patients and mean $( \pm S E)$, starting from base line to week 12 and week 24. After 12 weeks of $200 \mu \mathrm{g}$ VIP inhaled per day, the physical capacity improved significantly as compared with baseline $(P<0.01)$ and further improved $(P<0.01)$ when tested after 24 weeks of treatment.

patient who underwent lung transplantation $(n=3)$. Immunocytochemical staining for VPAC-1 and VPAC-2 in PASMCs showed consistently higher signal levels for the PPH group (Figure 4a). In the immunohistochemical staining for VPAC-1 and VPAC-2, a minimum of 50 pulmonary arteries with or without plexiform lesions for each group (control or PPH) was evaluated. Sections from PPH patients consistently revealed higher staining intensities as compared with controls (Figure 4b).

Membrane-bound VPAC-1 and VPAC-2 prepared from PASMCs were assessed by Western blot analysis showing a specific band of $49 \mathrm{kDa}$ for VPAC- 1 and 55 $\mathrm{kDa}$ for VPAC-2 in both controls and in PPH patients. The expression of VPAC-1 was increased approximately threefold and that of VPAC-2 approximately eightfold, as compared with controls (Figure 5a). Data obtained by Western blot analysis were validated by Northern blot analysis (Figure 5b).

We also used competitive receptor-binding studies with ${ }^{123} \mathrm{I}$-VIP to confirm the presence of two specific binding sites on primary cell cultures of PASMCs, both in controls (Figure 6a) and in PPH patients (Figure 6b), indicating the presence of two VIP receptor types in PASMCs. In controls $(n=3), K_{\mathrm{d}}$ was $25.68 \pm 3.11$ and $38.55 \pm 3.95 \mathrm{nM}$, respectively, corresponding to a $B_{\max }$ of $0.57 \pm 0.05$ and $0.58 \pm 0.04 \mathrm{pM} / 10^{6}$ cells, respectively. In contrast, the affinity of VIP binding to its receptors on PASMCs from $\mathrm{PPH}$ patients $(n=3)$ was much higher, with a $K_{\mathrm{d}}$ of $1.70 \pm 0.15$ and $0.36 \pm 0.13 \mathrm{nM}$, respectively, and a $B_{\max }$ of $0.89 \pm 0.07$ and $0.08 \pm 0.01 \mathrm{pM} / 10^{6}$ cells.

Growth-inhibiting potential of VIP in vitro. To examine the effectiveness of VIP in vitro, we characterized its ability to affect the proliferation of PASMCs. VIP inhibited basal proliferation of PASMCs from $\mathrm{PPH}$ patients $(n=3)$ (Figure 7). This inhibitory effect was dose dependent.

Clinical evaluation of VIP in PPH. We investigated safety and efficacy of VIP inhalation in eight PPH patients (two men, six women) without previous treatment of epoprostenol or prostacyclin analogues in a prospective, controlled, intraindividual study. The patient's characteristics are given in Table 1. All eight patients completed the study.

We tested all patients for acute response to VIP and NO. Before VIP inhalation, mean pulmonary arterial pressure (MPAP) was $59 \pm 8 \mathrm{mmHg}$ (mean $\pm \mathrm{SD}$ ), CO was $4.7 \pm 2 \mathrm{l} / \mathrm{min} / \mathrm{m}^{2}, \mathrm{SvO}_{2}$ was $58 \% \pm 7 \%$. The addition of $100 \mu \mathrm{g}$ inhaled VIP improved pulmonary hemodynamics in all patients tested. MPAP decreased by $10 \mathrm{mmHg}$ to $49 \pm 14 \mathrm{mmHg}(P<0.01)$. CO increased by $0.8 \mathrm{l} / \mathrm{min} / \mathrm{m}^{2}$ to $5.5 \mathrm{l} / \mathrm{min}^{1} / \mathrm{m}^{2}(P<0.05)$. $\mathrm{SvO}_{2}$ rose to $60 \% \pm 9 \%(P<0.05)$. Systemic arterial pressure and pulmonary capillary wedge pressure did not change significantly.

All patients demonstrated a negative acute vasodilator response to $\mathrm{NO}(<10 \mathrm{mmHg}$ decrease of MPAP and $<20 \%$ decrease of pulmonary vascular resistance by addition of $20 \mathrm{ppm} \mathrm{NO}$ ).

After 3 months of daily inhalation of a total of $200 \mu \mathrm{g}$ VIP in four single inhalations, mean pulmonary artery pressure decreased by $13 \mathrm{mmHg}$ from $59 \pm 8 \mathrm{mmHg}$ to $46 \pm 7 \mathrm{mmHg}(P<0.01)$ (Table 2$)$. Cardiac output increased by $1.7 \mathrm{l} / \mathrm{min}$ from $4.7 \pm 2.0$ to $6.4 \pm 1.6 \mathrm{l} / \mathrm{min}$ $(P<0.01)$. Pulmonary vascular resistance decreased by approximately $50 \%$ from $1,009 \pm 475$ dyne $/ \mathrm{s} / \mathrm{cm}^{5}$ to $586 \pm 165$ dyne $/ \mathrm{s} / \mathrm{cm}^{5}(P<0.01)$. Mixed venous oxygen saturation increased from $58 \% \pm 7 \%$ to $63 \% \pm 7 \%$ $(P<0.01)$. Mean systemic arterial pressure, heart rate, and pulmonary capillary wedge pressure remained unchanged. The 6-minute walk distance (27) increased by $113 \mathrm{~m}$, from $296 \pm 138$ to $409 \pm 102 \mathrm{~m}(P<0.01)$ after 12 weeks VIP treatment, and by $129 \mathrm{~m}$, from $296 \pm 138$ to $425 \pm 107 \mathrm{~m}(P<0.01)$, after 24 weeks VIP treatment (Figure 8), indicating a beneficial effect on the patients. The Borg dyspnea index (28) decreased by 0.5 , from $3.3 \pm 1.4$ to $2.8 \pm 1.2(P<0.01)$ (Table 2$)$ after

\section{Table 2}

Hemodynamic variables and exercise capacity in eight patients with $\mathrm{PPH}$ treated with inhaled VIPA

$\begin{array}{lcc}\text { Measurement } & \text { Baseline } & 3 \text { Months } \\ \text { Heart rate } & 78 \pm 12 & 75 \pm 13^{\mathrm{B}} \\ \text { Mean systemic arterial pressure (mmHg) } & 86 \pm 10 & 84 \pm 6^{\mathrm{B}} \\ \text { Mean pulmonary arterial pressure (mmHg) } & 59 \pm 8 & 46 \pm 7^{\mathrm{C}} \\ \text { Pulmonary capillary wedge pressure (mmHg) } & 9 \pm 2 & 9 \pm 2^{\mathrm{B}} \\ \text { Cardiac output (I/min) } & 4.7 \pm 2.0 & 6.4 \pm 1.6^{\mathrm{C}} \\ \text { Pulmonary vascular resistance } & 1009 \pm 475 & 586 \pm 165^{\mathrm{C}} \\ \text { (dyne/s/cm }) & & \\ \text { Mixed venous oxygen saturation (\%) } & 58 \pm 7 & 63 \pm 7^{\mathrm{C}} \\ \text { 6-Minute walk distance (m) } & 296 \pm 138 & 409 \pm 102^{\mathrm{C}} \\ \text { Dyspnea score (Borg index) } & 3.3 \pm 1.4 & 2.8 \pm 1.2^{\mathrm{C}}\end{array}$

AValues are mean \pm SD. ${ }^{B}$ Not significantly different. ${ }^{C} P<0.01$ for the comparison of preinhalation variables at 3 months with preinhalation variables at baseline. 
12 weeks, and by 0.6 , from $3.3 \pm 1.4$ to $2.7 \pm 1.3$ $(P<0.01)$, after 24 weeks of treatment.

\section{Discussion}

Using cell biological and clinical data we describe a pathophysiological role of VIP in PPH. This is evidenced from the following: ${ }^{123}$ I-VIP receptor scintigraphy of human organs shows a comparatively high density for VIP-binding sites in lung tissue. While we failed to detect VIP in the serum and tissue of PPH patients, the receptors were upregulated. The substitution by VIP results in significant improvement of pulmonary hemodynamics in PPH.

VIP functions as a potent vasodilator and bronchodilator $(11,30)$; it inhibits the proliferation of vascular and bronchial smooth muscle cells and decreases platelet aggregation (14). The hormone acts through two receptor subtypes (VPAC-1 and VPAC-2) coupled to adenylate cyclase $(14,31,32)$. VPAC-2 is abundant in various peripheral organs, including the lung vasculature (20). We identified the two receptors in PASMCs of $\mathrm{PPH}$ patients and demonstrated an increased expression in PPH whereby the level of expression was several-fold higher for VPAC-2. Also, the specific receptorbinding affinity in PASMCs from $\mathrm{PPH}$ patients was increased, which may reflect the lack of the hormone.

Stimulation of VPAC receptors leads to the activation of the cAMP and cGMP system. Analogously, cAMPand cGMP-dependent pathways have been shown to mediate the action of prostacyclins, NO, and phosphodiesterase inhibitors in the treatment of pulmonary hypertension $(5,21)$. The efficiency of these pharmacological agents is hampered, however, by the common observation of desensitization to treatment due to their pharmacokinetic and pharmacodynamic properties.

One of the cardinal features of pulmonary hypertension is increased growth of PASMCs and endothelial cells within pulmonary arteries (33). Increased growth was found to be related to an increase of $\left[\mathrm{Ca}^{2+}\right]_{i}$ in PASMCs from PPH patients (34). Our observation of an inhibitory effect of VIP on the increased proliferation in vitro supports our hypothesis that the peptide plays a fundamental pathophysiological role in PPH.

Our in vitro data are strengthened by the fact that the substitution of VIP improved virtually all parameters of the pulmonary circulation relevant for the prognosis of PPH $(13,35)$. Safety of VIP inhalation was shown in studies with healthy and asthmatic subjects using a VIP concentration of $100 \mu \mathrm{m}$ per day (36). The first tests carried out before the actual clinical trial were performed with intravenous and inhalative application (data not shown). Once we saw that the inhalative application was equally effective, however, we decided to stay with this easier approach. Taking into account the serum concentration and binding characteristics of VIP in control patients, we estimated an effective therapeutic concentration range of 100-200 $\mu \mathrm{g}$ per day for treatment of $\mathrm{PPH}$ and tested $200 \mu \mathrm{g}$ per day in the study. The application via inhalation may explain why virtually no patients revealed any side effects. The striking efficacy of VIP inhalation is stressed by both the significant increase of the mixed venous oxygen saturation and the increased exercise capacity in the 6-minute walk test. Considering the importance of these parameters for the prognosis of $\mathrm{PPH}$, and in agreement with a rabbit model (10), the inhalation of VIP may be used alone and/or in combination as an efficacious treatment of $\mathrm{PPH}$.

\section{Acknowledgments}

We wish to thank the Austrian Self Aid Group for Pulmonary Hypertension and the Austrian National Bank for their financial support.

1. Christman, B.W., McPherson, C.D., Newman, J.H., King, G.A., and Bernard, G.R. 1992. An imbalance between the excretion of thromboxane and prostacyclin metabolites in pulmonary hypertension. N. Engl. J. Med. 327:70-75.

2. Giaid, A., and Saleh, D. 1995. Reduced expression of endothelial nitric oxide synthase in the lungs of patients with pulmonary hypertension. N. Engl. J. Med. 333:214-221.

3. Giaid, A., et al. 1993. Expression of endothelin-1 in the lungs of patients with pulmonary hypertension. N. Engl. J. Med. 328:1732-1739.

4. Friedman, R., Mears, J.G., and Barst, R.J. 1997. Continuous infusion of prostacyclin normalizes plasma markers of endothelial cell injury and platelet aggregation in primary pulmonary hypertension. Circulation. 96:2782-2784.

5. Wharton, J., et al. 2000. Prostacyclin analogues differentially inhibit growth of distal and proximal human pulmonary artery smooth muscle cells. Circulation. 102:3130-3136.

6. Barst, R.J., et al. 1996. A comparison of continuous intravenous epoprostenol (prostacyclin) with conventional therapy for primary pulmonary hypertension. The Primary Pulmonary Hypertension Study Group. N. Engl.J. Med. 334:296-302.

7. Hoeper, M.M., et al. 2000. Long-term treatment of primary pulmonary hypertension with aerosolized iloprost, a prostacyclin analogue. N. Engl.J. Med. 342:1866-1870.

8. Nellgard, P., Bojo, L., and Cassuto, J. 1995. Importance of vasoactive intestinal peptide and somatostatin for fluid losses in small-bowel obstruction. Scand. J. Gastroenterol. 30:464-469.

9. Shuttleworth, T.J., and Thorndyke, M.C. 1984. An endogenous peptide stimulates secretory activity in the elasmobranch rectal gland. Science. 225:319-321.

10. Gunaydin, S., et al. 2002. The effects of vasoactive intestinal peptide on monocrotaline induced pulmonary hypertensive rabbits following cardiopulmonary bypass: a comparative study with isoproteronol and nitroglycerine. Cardiovasc. Surg. 10:138-145.

11. Greenberg, B., Rhoden, K., and Barnes, P.J. 1987. Relaxant effects of vasoactive intestinal peptide and peptide histidine isoleucine in human and bovine pulmonary arteries. Blood Vessels. 24:45-50.

12. Iwabuchi, S., Ono, S., Tanita, T., Koike, K., and Fujimura, S. 1997. Vasoactive intestinal peptide causes nitric oxide-dependent pulmonary vasodilation in isolated rat lung. Respiration. 64:54-58.

13. Soderman, C., et al. 1993. Effect of vasoactive intestinal polypeptide (VIP) on pulmonary ventilation-perfusion relationships and central haemodynamics in healthy subjects. Clin. Physiol. 13:677-685.

14. Cox, C.P., Linden, J., and Said, S.I. 1984. VIP elevates platelet cyclic AMP (cAMP) levels and inhibits in vitro platelet activation induced by plateletactivating factor (PAF). Peptides. 5:325-328.

15. Maruno, K., Absood, A., and Said, S.I. 1995. VIP inhibits basal and histamine-stimulated proliferation of human airway smooth muscle cells. Am. J. Physiol. 268:L1047-L1051.

16. Delgado, M., Abad, C., Martinez, C., Leceta, J., and Gomariz, R.P. 2001. Vasoactive intestinal peptide prevents experimental arthritis by downregulating both autoimmune and inflammatory components of the disease. Nat. Med. 7:563-569.

17. Ishihara, T., Shigemoto, R., Mori, K., Takahashi, K., and Nagata, S. 1992. Functional expression and tissue distribution of a novel receptor for vasoactive intestinal polypeptide. Neuron. 8:811-819.

18. Raderer, M. 1998. Iodine-123-vasoactive intestinal peptide receptor scanning in patients with pancreatic cancer. J. Nucl. Med. 39:1570-1575.

19. Usdin, T.B., Bonner, T.I., and Mezey, E. 1994. Two receptors for vasoactive intestinal polypeptide with similar specificity and complementary distributions. Endocrinology. 135:2662-2680.

20. Busto, R., Prieto, J.C., Bodega, G., Zapatero, J., and Carrero, I. 2000. 
Immunohistochemical localization and distribution of VIP/PACAP receptors in human lung. Peptides. 21:265-269.

21. Horstman, D.J., McCall, D.A., Frank, D.U., and Rich, G.F. 1999. Inhaled nitric oxide and nifedipine have similar effects on lung cGMP levels in rats. Anesth. Analg. 89:932-937.

22. Koch, T.R., Michener, S.R., and Go, V.L. 1991. Plasma vasoactive intestinal polypeptide concentration determination in patients with diarrhea. Gastroenterology. 100:99-106.

23. Bradford, M.M. 1976. A rapid and sensitive method for the quantitation of microgram quantities of protein utilizing the principle of protein-dye binding. Anal. Biochem. 72:248-254.

24. Scatchard, G. 1949. The attractions of protein for small molecules and ions. Ann. N. Y. Acad. Sci. 51:660-666.

25. Skarstein, K., Nerland, A.H., Eidsheim, M., Mountz, J.D., and Jonsson, R. 1997. Lymphoid cell accumulation in salivary glands of autoimmune MRL mice can be due to impaired apoptosis. Scand. J. Immunol. 46:373-378.

26. Rich, S., et al. 1987. Primary pulmonary hypertension. A national prospective study. Ann. Intern. Med. 107:216-223.

27. Guyatt, G.H., et al. 1985. The 6-minute walk: a new measure of exercise capacity in patients with chronic heart failure. Can. Med. Assoc. J. 132:919-923.

28. Borg, G.A. 1982. Psychophysical bases of perceived exertion. Med. Sci. Sports Exerc. 14:377-381.

29. Busto, R., Carrero, I., Bodega, G., Zapatero, J., and Prieto, J.C. 2000.
Immunohistochemical and immunochemical evidence for expression of human lung PACAP/VIP receptors. Ann. N. Y. Acad. Sci. 921:308-311.

30. Saga, T., and Said, S.I. 1984. Vasoactive intestinal peptide relaxes isolated strips of human bronchus, pulmonary artery, and lung parenchyma. Trans. Assoc. Am. Physicians. 97:304-310.

31. Gagnon, A.W., Aiyar, N., and Elshourbagy, N.A. 1994. Molecular cloning and functional characterization of a human liver vasoactive intestinal peptide receptor. Cell Signal. 6:321-333.

32. Sreedharan, S.P., Robichon, A., Peterson, K.E., and Goetzl, E.J. 1991. Cloning and expression of the human vasoactive intestinal peptide receptor. Proc. Natl. Acad. Sci. U. S. A. 88:4986-4990.

33. Morrell, et al. 2001. Altered growth responses of pulmonary artery smooth muscle cells from patients with primary pulmonary hypertension to transforming growth factor-beta(1) and bone morphogenetic proteins. Circulation. 104:790-795.

34. Platoshyn, O., et al. 2000. Sustained membrane depolarization and pulmonary artery smooth muscle cell proliferation. Am. J. Physiol. Cell Physiol. 279:C1540-C1549.

35. Maxwell, D.L., Fuller, R.W., Dixon, C.M., Cuss, F.M., and Barnes, P.J. 1990. Ventilatory effects of substance $P$, vasoactive intestinal peptide, and nitroprusside in humans. J. Appl. Physiol. 68:295-301.

36. Barnes, P.J., and Dixon, C.M. 1984. The effect of inhaled vasoactive intestinal peptide on bronchial reactivity to histamine in humans. Am. Rev. Respir. Dis. 130:162-166. 